\title{
Associations between Health-Related Fitness and Cardio-Metabolic Blood Profiles in Low-Income Children
}

\author{
Ryan D. Burns', Timothy A. Brusseau1, You Fu², James C. Hannon ${ }^{3}$ \\ ${ }^{1}$ Department of Exercise and Sport Science, University of Utah, Salt Lake City, USA \\ ${ }^{2}$ Kinesiology and Sport Science Department, University of Nebraska Kearney, Kearney, USA \\ ${ }^{3}$ College of Physical Activity and Sport Sciences, West Virginia University, Morgantown, USA \\ Email: ryan.d.burns@utah.edu
}

Received 23 August 2015; accepted 19 September 2015; published 22 September 2015

Copyright (C) 2015 by authors and Scientific Research Publishing Inc.

This work is licensed under the Creative Commons Attribution International License (CC BY).

http://creativecommons.org/licenses/by/4.0/

(c) (i) Open Access

\section{Abstract}

Children from low-income families have a higher incidence for developing early onset cardiometabolic disease risk factors. Optimal levels of health-related fitness may attenuate risk, but little research has examined its relationships with individual cardio-metabolic blood markers in low-income children. The purpose of this study was to examine the prevalence and correlates of unfavorable cardio-metabolic blood profiles in children from low-income families. Data were collected and analyzed on 124 children (mean age = 10.4 \pm 0.9 years; 57 girls, 67 boys; $97 \%$ Hispanic) recruited from three urban Title I schools from the state of Utah in the US Health-related fitness. Measures were collected using the validated FITNESSGRAM fitness test battery. The Cholestech LDX system was used to analyze students' total cholesterol (TC), LDL cholesterol, HDL cholesterol, triglycerides (TRI), and blood glucose (BG). Capillary blood samples via finger sticks were collected while each student was in a fasted state before school hours. Unfavorable measurements were defined as TC $\geq 200 \mathrm{mg} / \mathrm{dL}$, LDL $\geq 130 \mathrm{mg} / \mathrm{dL}$, HDL $<40 \mathrm{mg} / \mathrm{dL}$, TRI $>150 \mathrm{mg} / \mathrm{dL}$, and BG $\geq$ $100 \mathrm{mg} / \mathrm{dL}$ (pre-diabetes). Approximately $5.3 \%$ of the total sample had unfavorable TC, $16.7 \%$ had unfavorable HDL, $16.0 \%$ had unfavorable LDL, $15.2 \%$ had unfavorable TRI, and $25.4 \%$ had unfavorable BG (pre-diabetes). Pearson's chi-square tests revealed no significant differences between sexes on any unfavorable classification after alpha level adjustment $(p>0.01)$. When all parameters were analyzed as continuous variables, Spearman's rank correlation revealed a statistically significant linear relationship between aerobic fitness and LDL in boys $\left(r_{s}=-0.65, p<0.01\right)$, between BMI and HDL in girls $\left(r_{s}=-0.46, p<0.01\right)$, and between BMI and BG in girls $\left(r_{s}=0.56, p<\right.$ 0.01). Aerobic fitness relates to LDL cholesterol in low-income boys and BMI relates to HDL cholesterol and BG in low-income girls. 


\section{Keywords}

\section{Aerobic Fitness, Blood Glucose, Body Mass Index, Cholesterol}

\section{Introduction}

In recent decades, the health of youth in the US has been on a decline. Excess sedentary behaviors and overweight and obesity rates have steadily increased since the 1980's and by 2020 it is projected that $52 \%$ of adults will have developed Type II diabetes or pre-diabetes, which is linked to an increased mortality rate [1]-[3]. A pediatric sub-population where the prevalence of overweight and obesity and corresponding metabolic disorders is substantially higher is within the low socio-economic status (SES) population [4], where the prevalence of obesity is approximately $9.2 \%$ greater for boys and $7.3 \%$ greater in girls compared to higher SES children [5] [6]. In order to attenuate the incidence of cardio-metabolic diseases that increase morbidity and mortality, effective preventive strategies must be devised at an early age.

Health-related fitness has been shown to have a protective effect on the incidence of cardio-metabolic risk factors in children [7]-[10]. Health-related fitness consists of five domains including body composition, aerobic fitness, muscular strength and endurance, and flexibility. Body composition and aerobic fitness are the two domains that tend to have the strongest relationships with health outcomes in the pediatric population [11]-[15]. Because of the established relationships between health-related fitness and various health markers, improving health related fitness levels has become imperative to attenuate risk of developing chronic disease.

The relationship between fitness and health has been studied extensively in the pediatric population [11]-[15]; however research examining the link between specific domains of health-related fitness, particularly aerobic fitness and body composition, with cardio-metabolic risk in disadvantaged children from low SES families is lacking. Families and children are defined as low-income (i.e. low SES) if income is less than twice the federal poverty threshold. There is evidence that low SES children may have unfavorable levels health-related fitness because of the lack of resources (i.e. play space, after school activities, etc.) and parental support needed to sustain healthy physical activity behaviors throughout childhood and into adolescence [16] [17]. Lower levels of health-related fitness may be related to unfavorable cardio-metabolic blood profiles. Given the lack of research examining the relationships between health-related fitness and cardio-metabolic risk in low-income children, the purpose of this study was to 1) examine the prevalence of unfavorable cardio-metabolic blood profiles, and 2) examine the associations between health-related fitness (aerobic fitness and body composition) with cardio-metabolic blood profiles in disadvantaged children from low-income families.

\section{Methods}

\subsection{Participants}

Participants were a convenience sample of 124 school-aged children recruited from three urban Title I elementary schools located in low SES neighborhoods from the state of Utah in the US. Over 95\% of the children at each of the three schools were from low-income families. Children were recruited from the $3^{\text {rd }}-6^{\text {th }}$ grades. The mean age of the sample was $10.4 \pm 0.9$ years and there were 57 girls and 67 boys who participated. Written assent was obtained from the students and written consent was obtained from the parents prior to data collection. The University Institutional Review Board approved the protocols employed in this study.

\subsection{Cardio-Metabolic Measures}

Each student's cardio-metabolic profile was collected using the Cholestech LDX system (Alere Inc., Waltham, MA, USA). Individual measurements included total cholesterol (TC), LDL cholesterol, HDL cholesterol, triglycerides (TRI), and blood glucose (BG). A capillary blood sample was collected between the hours of 6 am and $8 \mathrm{am}$ before the commencement of the school day. Blood samples were collected in a fasted state, verbally verified by both the student and the student's parent or guardian prior to collection of the blood sample. Blood samples were collected via a finger stick on each student's right index finger using a $40-\mu \mathrm{L}$ capillary tube and immediately injected into the Lipid Profile-Glucose Cassette (Alere Inc., Waltham, MA, USA) and subsequently 
analyzed. The puncture site was cleaned and bandaged and all materials were properly disposed of in a biohazard container.

\subsection{Health-Related Fitness Measures}

Body composition was measured using Body Mass Index (BMI). BMI was calculated using standard procedures taking a student's weight in kilograms divided by the square or his or her height in meters. Height was measured to the nearest 0.01 meters using a portable stadiometer (Seca 213; Hanover, MD, USA) and weight was measured to the nearest 0.1 kilogram using a portable medical scale (BD-590; Tokyo, Japan). Height and weight were collected 2-hours post-prandial in a private room during each student's physical education class before any physical activity. The student's shoes were taken off but clothes were left on while collecting the height and weight measurements.

Aerobic fitness was measured using the 20-meter Progressive Aerobic Cardiovascular Endurance Run (PACER), administered during each student's physical education class. The PACER was conducted on a marked gymnasium floor with background music and cadence provided on a compact disk. Each student was instructed to run from one floor marker to another floor marker across a 20-meter distance within an allotted time frame. The allotted time given to reach the specified distance incrementally shortened as the test progressed. If the student twice failed to reach the other floor marker, the test was terminated [18]. The final score was recorded in laps.

\subsection{Data Processing}

Continuous variables were screened for outliers using box plots and $z$-scores (with $a \pm 2.5 z$ cutoff) and checked for Gaussian distributions using $k$-density plots. The cardio-metabolic continuous variable scores were also stratified into a binary classification scheme based on guidelines recommended by the National Cholesterol Education Program and the American Diabetes Association [19] [20]. Unfavorable cardio-metabolic measurements were defined as TC $\geq 200 \mathrm{mg} / \mathrm{dL}, \mathrm{LDL} \geq 130 \mathrm{mg} / \mathrm{dL}, \mathrm{HDL}<40 \mathrm{mg} / \mathrm{dL}, \mathrm{TRI}>150 \mathrm{mg} / \mathrm{dL}$, and $\mathrm{BG} \geq 100$ $\mathrm{mg} / \mathrm{dL}$ (pre-diabetes).

\subsection{Statistical Analysis}

The preliminary analysis involved examining the differences between the sexes on health-related fitness and cardio-metabolic measures using independent t-tests. Pearson's chi-square tests were used to test for age and sex differences in the number of children who had unfavorable blood marker profiles for each measure. The alpha level was adjusted using the Bonferroni method to correct for multiple comparisons. The $k$-density plots revealed significant positive skewness for BMI and PACER scores; therefore non-parametric statistical tests were used to examine the relationships. To examine the rank order linear relationships between each health-related fitness measure and each cardio-metabolic blood marker, Spearman's rank correlations were employed within each sex group. All analyses assumed an initial alpha level of $p \leq 0.01$ and were carried out using STATA v14.0 statistical software program (College Station, TX, USA).

\section{Results}

Table 1 presents the socio-demographic characteristics of the sample. Approximately $96 \%$ of the sample was from low-income families and approximately $97 \%$ of the sample was of an ethnic minority. The descriptive statistics for the total sample and within each sex group are presented in Table 2. In this sample, girls had higher BMI compared to boys (Mean difference $=1.8 \mathrm{~kg} / \mathrm{m}^{2}, p<0.01$ ) and boys had higher fasting HDL cholesterol (mean difference $=5.6 \mathrm{mg} / \mathrm{dL}, p<0.01$ ) and ran more PACER laps (mean difference $=5.1$ laps, $p<0.01$ ). There were no other significant differences found between the sexes on any other measurement. Approximately $5.3 \%$ of the total sample had unfavorable TC, $16.7 \%$ had unfavorable HDL cholesterol, $16.0 \%$ had unfavorable LDL cholesterol, $15.2 \%$ had unfavorable TRI, and $25.4 \%$ had unfavorable BG (pre-diabetes). Pearson's chi-square tests revealed no significant differences between sexes on any unfavorable classification after alpha level adjustment $(p>0.01)$. There were also no differences among grade levels on unfavorable blood profile classification $(p>0.01)$. Table 3 and Table 4 show the Spearman rank correlation coefficients for girls and boys, respectively. When all parameters were analyzed as continuous variables, Spearman's rank correlation revealed a statistically significant linear relationship between aerobic fitness (PACER laps) and LDL 
Table 1. Socio-demographic characteristics.

\begin{tabular}{cccc}
\hline & $\begin{array}{c}\text { Total sample } \\
(\mathrm{N}=124)\end{array}$ & $\begin{array}{c}\text { Girls } \\
(\mathrm{n}=57)\end{array}$ & $\begin{array}{c}\text { Boys } \\
(\mathrm{n}=67)\end{array}$ \\
\hline Age (years) & $10.4(0.9)$ & $10.4(0.8)$ & $10.4(1.0)$ \\
Low-income & $119 / 124(96 \%)$ & $54 / 57(95 \%)$ & $65 / 67(97 \%)$ \\
Ethnic minority & $120 / 124(97 \%)$ & $56 / 57(98 \%)$ & $64 / 67(96 \%)$ \\
\hline
\end{tabular}

Table 2. Descriptive statistics for the total sample and within sex groups (means and standard deviations).

\begin{tabular}{|c|c|c|c|}
\hline & $\begin{array}{l}\text { Total sample } \\
(\mathrm{N}=124)\end{array}$ & $\begin{array}{c}\text { Girls } \\
(\mathrm{n}=57)\end{array}$ & $\begin{array}{c}\text { Boys } \\
(\mathrm{n}=67)\end{array}$ \\
\hline \multicolumn{4}{|l|}{ Health-related fitness } \\
\hline $\mathrm{BMI}^{\mathrm{a}}\left(\mathrm{kg} / \mathrm{m}^{2}\right)$ & $18.5(3.8)$ & $19.3(4.0)^{\dagger}$ & $17.5(3.2)$ \\
\hline PACER $^{\mathrm{b}}$ laps & $26.4(16.1)$ & $23.6(13.6)$ & 28. $7(17.7)$ \\
\hline \multicolumn{4}{|l|}{ Blood markers } \\
\hline $\mathrm{TC}^{\mathrm{c}}(\mathrm{mg} / \mathrm{dL})$ & $150.8(24.4)$ & $150.3(24.9)$ & $151.5(23.9)$ \\
\hline LDL $^{\mathrm{d}}$ cholesterol (mg/dL) & $76.4(25.6)$ & $77.2(24.0)$ & $75.2(26.0)$ \\
\hline $\mathrm{HDL}^{\mathrm{e}}$ cholesterol (mg/dL) & $53.5(13.2)$ & $51.1(12.2)$ & $56.7(13.9)^{\dagger}$ \\
\hline $\mathrm{TRI}^{\mathrm{f}}(\mathrm{mg} / \mathrm{dL})$ & $108.7(59.9)$ & $116.3(56.1)$ & $97.8(64.0)$ \\
\hline $\mathrm{BG}^{\mathrm{g}}(\mathrm{mg} / \mathrm{dL})$ & $92.7(11.8)$ & $93.3(13.1)$ & $91.9(9.6)$ \\
\hline
\end{tabular}

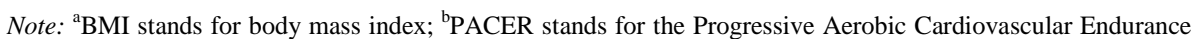
Run; ${ }^{\mathrm{C}} \mathrm{TC}$ stands for fasting total cholesterol; ${ }^{\mathrm{d}} \mathrm{LDL}$ stands for fasting LDL cholesterol; ${ }^{\mathrm{H}} \mathrm{HDL}$ stands for fasting HDL cholesterol; ${ }^{\mathrm{f}} \mathrm{TRI}$ stands for fasting triglycerides; ${ }^{\mathrm{g}} \mathrm{BG}$ stands for fasting blood glucose; bold denotes statistical significance, ${ }^{\dagger} p<0.01$.

Table 3. Spearman's rank correlations between health-related fitness and cardio-metabolic parameters in girls.

\begin{tabular}{cccccccc}
\hline & BMI $^{\mathrm{a}}$ & PACER $^{\mathrm{b}}$ Laps & $\mathrm{TC}^{\mathrm{c}}$ & $\mathrm{LDL}^{\mathrm{d}}$ & $\mathrm{HDL}^{\mathrm{e}}$ & $\mathrm{TRI}^{\mathrm{f}}$ & $\mathrm{BG}^{\mathrm{g}}$ \\
\hline $\mathrm{BMI}^{\mathrm{a}}\left(\mathrm{kg} / \mathrm{m}^{2}\right)$ & 1 & & & & & & \\
$\mathrm{PACER}^{\mathrm{b}} \mathrm{Laps}$ & 0.03 & 1 & & & & & \\
$\mathrm{TC}^{\mathrm{c}}(\mathrm{mg} / \mathrm{dL})$ & -0.14 & -0.22 & 1 & & & & \\
$\mathrm{LDL}^{\mathrm{d}}(\mathrm{mg} / \mathrm{dL})$ & -0.04 & -0.27 & $\mathbf{0 . 7 4}^{\dagger}$ & 1 & & & \\
$\mathrm{HDL}^{\mathrm{e}}(\mathrm{mg} / \mathrm{dL})$ & $-\mathbf{0 . 4 6}$ & -0.11 & $\mathbf{0 . 3 4}^{\dagger}$ & -0.12 & 1 & & \\
$\mathrm{TRI}^{\mathrm{f}}(\mathrm{mg} / \mathrm{dL})$ & 0.27 & 0.13 & -0.01 & -0.22 & -0.28 & 1 & \\
$\mathrm{BG}^{\mathrm{g}}(\mathrm{mg} / \mathrm{dL})$ & $\mathbf{0 . 5 6}$ & 0.07 & -0.27 & -0.15 & -0.17 & 0.14 & 1 \\
\hline
\end{tabular}

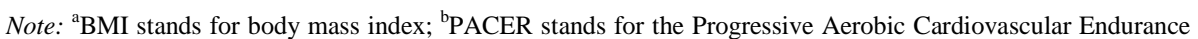
Run; ${ }^{\mathrm{C}} \mathrm{TC}$ stands for fasting total cholesterol; ${ }^{\mathrm{d}} \mathrm{LDL}$ stands for fasting LDL cholesterol; ${ }^{\mathrm{e}} \mathrm{HDL}$ stands for fasting HDL cholesterol; ${ }^{\mathrm{f}}$ TRI stands for fasting triglycerides; ${ }^{\mathrm{g}} \mathrm{BG}$ stands for fasting blood glucose; bold denotes statistical significance, ${ }^{\dagger} p<0.01$.

cholesterol in boys ( $\left.r_{s}=-0.65, p<0.01\right)$, between BMI and HDL cholesterol in girls $\left(r_{s}=-0.46, p<0.01\right)$, and between BMI and BG in girls $\left(\mathrm{r}_{\mathrm{s}}=0.56, p<0.01\right)$.

\section{Discussion}

The purpose of this study was to examine the prevalence of unfavorable cardio-metabolic blood profiles and to examine the relationship between health-related fitness and cardio-metabolic blood profiles in children from low-income families. The results indicated that higher levels of aerobic fitness were related to lower LDL cholesterol in boys and higher levels of BMI was related to lower HDL cholesterol and higher BG in girls. This 
Table 4. Spearman's rank correlations between health-related fitness and cardio-metabolic parameters in boys.

\begin{tabular}{cccccccc}
\hline & BMI $^{\mathrm{a}}$ & PACER $^{\mathrm{b}}$ Laps & $\mathrm{TC}^{\mathrm{c}}$ & $\mathrm{LDL}^{\mathrm{d}}$ & $\mathrm{HDL}^{\mathrm{e}}$ & $\mathrm{TRI}^{\mathrm{f}}$ & $\mathrm{BG}^{\mathrm{g}}$ \\
\hline $\mathrm{BMI}^{\mathrm{a}}\left(\mathrm{kg} / \mathrm{m}^{2}\right)$ & 1 & & & & & & \\
$\mathrm{PACER}^{\mathrm{b}} \mathrm{laps}$ & -0.21 & 1 & & & & & \\
$\mathrm{TC}^{\mathrm{c}}(\mathrm{mg} / \mathrm{dL})$ & -0.05 & -0.14 & 1 & & & & \\
$\mathrm{LDL}^{\mathrm{d}}(\mathrm{mg} / \mathrm{dL})$ & 0.01 & $-\mathbf{0 . 6 5}$ & $\mathbf{0 . 7 0}^{\dagger}$ & 1 & & & \\
$\mathrm{HDL}^{\mathrm{e}}(\mathrm{mg} / \mathrm{dL})$ & 0.10 & -0.03 & $\mathbf{0 . 5 5}$ & -0.01 & 1 & & \\
$\mathrm{TRI}^{\mathrm{f}}(\mathrm{mg} / \mathrm{dL})$ & -0.37 & -0.02 & -0.21 & -0.18 & -0.16 & 1 \\
$\mathrm{BG}^{\mathrm{g}}(\mathrm{mg} / \mathrm{dL})$ & 0.04 & 0.31 & 0.05 & 0.13 & 0.04 & -0.09 & 1 \\
\hline
\end{tabular}

Note: ${ }^{\mathrm{a}} \mathrm{BMI}$ stands for body mass index; ${ }^{\mathrm{b}} \mathrm{PACER}$ stands for the Progressive Aerobic Cardiovascular Endurance Run; ${ }^{\mathrm{C}} \mathrm{TC}$ stands for fasting total cholesterol; ${ }^{\mathrm{d}} \mathrm{LDL}$ stands for fasting LDL cholesterol; ${ }^{\mathrm{e}} \mathrm{HDL}$ stands for fasting HDL cholesterol; ${ }^{\mathrm{f}} \mathrm{TRI}$ stands for fasting triglycerides; ${ }^{\text {g}} \mathrm{BG}$ stands for fasting blood glucose; bold denotes statistical significance, ${ }^{\mathrm{P}} p<0.01$.

study provides information on the prevalence of unfavorable cardio-metabolic blood profiles and how healthrelated fitness levels relate to these parameters in disadvantaged children from low-income families.

Research linking health-related fitness with cardio-metabolic risk is conflicting in the current literature. Some studies suggest that optimal levels of health-related fitness, specifically aerobic fitness, have a protective effect on cardio-metabolic risk, even if a child is overweight [7] [21]. However, other studies have shown that the relationship between aerobic fitness and cardio-metabolic risk is mediated by abdominal adiposity [22], while others have shown that fitness and risk is mediated by BMI [23]. Brouwer et al. [24] found that aerobic fitness and fatness both independently related to a clustered cardio-metabolic risk score in a relatively large sample of 16-year old boys, but the independent effect of aerobic fitness was not found in girls. This study provided evidence that aerobic fitness may be more relevant to boys, while fatness may be more relevant to girls in the context of attenuating cardio-metabolic risk. Despite the paucity of research examining these relationships in younger samples of children, the consensus in the research community is that both aerobic fitness and body composition influence cardio-metabolic risk in children and adolescents, but the magnitude of the independent effect of each on specific cardio-metabolic measurements is questionable and may be confounded by sex and age [25].

The results from this study indicated that specific domains of health-related fitness relate differently to cardio-metabolic blood profiles in girls and boys. Aerobic fitness, measured using the validated PACER test, significantly related to LDL cholesterol in boys, and BMI significantly related to HDL cholesterol and BG in girls. Past research has shown that elevated levels of aerobic fitness are associated with lower levels of LDL cholesterol in children [26]. The current study supports these findings but this phenomenon was only evident in boys. In girls, BMI was the health-related fitness domain that related to cardio-metabolic parameters. BMI, an index for body composition, is widely used for body composition assessment in clinical and physical education settings. Higher levels of BMI has been associated with blood sugar abnormalities and increased cardio-metabolic risk but recent evidence suggests that these relationships may be specific to girls [27]. BMI may be a more valid measure of body composition to serve as a proxy for cardio-metabolic risk in young girls, as in boys there were no associations between BMI and any cardio-metabolic blood marker. These relationships may have been influenced by the higher levels of aerobic fitness found in boys, which may attenuate risk and confound the relationship between body composition and health. Additionally, past research has shown other body composition measures such as waist circumference and waist-to-height ratio may have stronger relationships with cardiometabolic risk than BMI [28] [29]. This may be because BMI does not distinguish fat mass from fat-free mass and waist circumference may capture visceral adipose deposits that have been shown to correlate stronger with cardio-metabolic health compared to sub-cutaneous fat deposits [29]. Unfortunately, these measures were not collected and may be a priority for future research studies using samples of low-income children.

The prevalence of unfavorable BG levels in this sample was especially high, and 100 of the 124 children in this study's sample had at least one unfavorable blood lipid marker. A recent study using 1999-2008 NHANES data showed that $15 \%$ of adolescents have pre-diabetes or diabetes [30]. Additionally, $6 \%$ showed low HDL cholesterol and 22\% showed high LDL cholesterol [30]. The current study, using a younger sample, clearly showed that in low-income children a higher prevalence of unfavorable BG and HDL cholesterol was found 
compared to [30]. A major limitation to the current study was the limited sample size and use of a convenience sampling method, however it does provide evidence that younger low-income children may have a higher prevalence of unfavorable cardio-metabolic blood profiles compared to older and higher SES children. These findings supplement the information relating the specific domains of health-related fitness with cardio-metabolic blood markers.

The results support the importance of optimizing health-related fitness. Aerobic fitness may be more relevant for cardio-metabolic health in boys and BMI may be more relevant in girls. This stresses the importance for children to participate in school and after school physical activity to improve their health-related fitness levels. Future research should focus on the longitudinal relationships among these parameters, controlling for various factors such as physical activity levels, family income, and availability of play space and play time in school settings.

\section{Conclusion}

In conclusion, higher levels of aerobic fitness were related to lower LDL cholesterol in boys and higher levels of BMI were related to lower HDL cholesterol and higher BG in girls. This study adds to the body of knowledge supporting that the manifestation of cardio-metabolic risk may develop earlier in lower SES populations of children and that specific domains of health-related fitness may relate to blood markers differently in girls and boys.

\section{Acknowledgements}

All authors would like to thank the students who participated in this study.

\section{References}

[1] Ogden, C.L., Carroll, M.D., Kit, B.K. and Flegal, K.M. (2014) Prevalence of Childhood and Adult Obesity in the United States, 2011-2012. Journal of the American Medical Association, 311, 806-814. http://dx.doi.org/10.1001/jama.2014.732

[2] National Center for Health Statistics (2012) Health, United States, 2011: With Special Features on Socioeconomic Status and Health. U.S. Department of Health and Human Services, Hyattsville.

[3] United Health Center for Health Reform and Modernization (2010) The United States of Diabetes: Challenges and Opportunities for the Decade Ahead. Author, Minnetonka.

[4] Ogden, C.L., Lamb, M.M., Carroll, M.D. and Flegal, K.M. (2010) Obesity and Socioeconomic Status in Children: United States 1988-1994 and 2005-2008. NCHS Data Brief No. 51. National Center for Health Statistics, Hyattsville.

[5] Wang, Y. and Zhang, Q. (2006) Are American Children and Adolescents of Low Socioeconomic Status at Increased Risk of Obesity? Changes in the Association between Overweight and Family Income between 1971 and 2002. American Journal of Clinical Nutrition, 84, 707-716.

[6] Jin, Y. and Jones-Smith, J.C. (2015) Associations between Family Income and Children's Physical Fitness and Obesity in California, 2010-2012. Preventing Chronic Disease, 12, Article ID: 140392. http://dx.doi.org/10.5888/pcd12.140392

[7] Eisenmann, J.C., Welk, G.J., Ihmels, M. and Dollman, J. (2007) Fatness, Fitness, and Cardiovascular Disease Risk Factors in Children and Adolescents. Medicine and Science in Sports and Exercise, 39, 1251-1256. http://dx.doi.org/10.1249/MSS.0b013e318064c8b0

[8] Jago, R., Drews, K.L., McMurray, R.G., et al. (2010) Fatness, Fitness and Cardio-Metabolic Risk Factors among Sixth-Grade Youth. Medicine and Science in Sports and Exercise, 42, 1502-1510. http://dx.doi.org/10.1249/MSS.0b013e3181d322c4

[9] Durant, R.H., Linder, C.W., Harkess, J.W. and Gray, R.G. (1983) The Relationship between Physical Activity and Serum Lipids and Lipoproteins in Black Children and Adolescents. Journal of Adolescent Health Care, 4, 55-60. http://dx.doi.org/10.1016/S0197-0070(83)80231-9

[10] Vaisto, J., Eloranta, A.M., Viitasalo, A., et al. (2014) Physical Activity and Sedentary Behavior in Relation to CardioMetabolic Risk in Children: Cross-Sectional Findings from the Physical Activity and Nutrition in Children (PANIC) Study. International Journal of Behavioral Nutrition and Physical Activity, 11, 55. http://dx.doi.org/10.1186/1479-5868-11-55

[11] McKenzie, T.L., Marshall, S.J., Sallis, J.F. and Conway, T.L. (2000) Leisure-Time Physical Activity in School Environments: An Observational Study Using SOPLAY. Preventive Medicine, 30, 70-77. http://dx.doi.org/10.1006/pmed.1999.0591 
[12] Nadar, P.R., Bradley, R.H., Houts, R.M., McRitchie, S.L. and O’Brian, M. (2008) Moderate-to-Vigorous Physical Activity from Ages 9 to 15 Years. Journal of the American Medical Association, 300, 295-305. http://dx.doi.org/10.1001/jama.300.3.295

[13] Dumith, S.C., Gigante, D.P., Domingues, M.R. and Kohl, H.W. (2011) Physical Activity Change during Adolescence: A Systematic Review and a Pooled Analysis. International Journal of Epidemiology, 40, 1-14. http://dx.doi.org/10.1093/ije/dyq272

[14] Armstrong, N., Tomkinson, G. and Ekelund, U. (2011) Aerobic Fitness and Its Relationship to Sport, Exercise Training and Habitual Physical Activity during Youth. British Journal of Sports Medicine, 45, 849-858. http://dx.doi.org/10.1136/bjsports-2011-090200

[15] Duncan, S.C., Duncan, T.E., Strycker, L.A. and Chaumeton, N. (2007) A Cohort-Sequential Latent Growth Model of Physical Activity from Ages 12 to 17 Years. Annals of Behavioral Medicine, 33, 80-89. http://dx.doi.org/10.1207/s15324796abm3301_9

[16] Lampard, A.M., Jurkowski, J.M., Lawson, H.A. and Davison, K.K. (2013) Family Ecological Predictors of Physical Activity Parenting in Low-Income Families. Behavioral Medicine, 39, 97-103. http://dx.doi.org/10.1080/08964289.2013.802215

[17] Messiah, S.E., Arheart, K.L., Lopez-Mitnik, G., Lipshultz, S.E. and Miller, T.L. (2013) Ethnic Group Differences in Cardio-Metabolic Disease Risk Factors Independent of Body Mass Index. Obesity, 21, 424-428. http://dx.doi.org/10.1002/oby.20343

[18] Meredith, M.D. and Welk, G.J. (2010) Fitnessgram/Actvitygram Test Administration Manual. 4th Edition, Human Kinetics, Champaign.

[19] Expert Panel on Detection, Evaluation, and Treatment of High Blood Cholesterol in Adults (2001) Executive Summary of the Third Report of the National Cholesterol Education Program (NCEP) Expert Panel on Detection, Evaluation, and Treatment of High Blood Cholesterol in Adults (Adult Treatment Panel III). Journal of the American Medical Association, 285, 2486-2497.

[20] Expert Committee on the Diagnosis and Classification of Diabetes Mellitus (2002) American Diabetes Association: Clinical Practice Recommendations 2002. Diabetes Care, 25, S1-S147. http://dx.doi.org/10.2337/diacare.25.2007.S1

[21] Adegboye, A.R., Anderssen, S.A., Froberg, K., et al. (2011) Recommended Aerobic Fitness Level for Metabolic Health in Children and Adolescents: A Study of Diagnostic Accuracy. British Journal of Sports Medicine, 45, 722-728. http://dx.doi.org/10.1136/bjsm.2009.068346

[22] Baily, D.P., Savory, L.A., Denton, S.J. and Kerr, C.J. (2014) The Association between Cardiorespiratory Fitness and Cardio-Metabolic Risk in Children Is Mediated by Abdominal Adiposity: The HAPPY Study. Journal of Physical Activity and Health, Epub Ahead of Print. http://dx.doi.org/10.1123/jpah.2014-0311

[23] Díez-Fernández, A., Sánchez-López, M. and Gulías-González, R., et al. (2015) BMI as a Mediator of the Relationship between Muscular Fitness and Cardio-Metabolic Risk in Children: A Mediation Analysis. PLoS ONE, 10, e0116506.

[24] Brouwer, S.I., Stolk, R.P., Liem, E.T., Lemmink, K. and Corpeleijn, E. (2012) The Role of Fitness in the Association between Fatness and Cardio-Metabolic risk from Childhood to Adolescence. Pediatric Diabetes, 14, 57-65. http://dx.doi.org/10.1111/j.1399-5448.2012.00893.x

[25] Gaesser, G.A., Tucker, W.J., Jarrett, C.L. and Angadi, S.S. (2015) Fitness versus Fatness: Which Influences Health and Mortality Risk the Most? Current Sports Medicine Reports, 14, 327-332. http://dx.doi.org/10.1249/JSR.0000000000000170

[26] Tolfrey, K., Jones, A.M. and Campbell, I.G. (2000) The Effect of Aerobic Exercise Training on the Lipid-Lipoprotein Profile of Children and Adolescents. Sports Medicine, 29, 99-112. http://dx.doi.org/10.2165/00007256-200029020-00003

[27] Mehdad, S., Hamrani, A., Kari, K.E., et al. (2012) Body Mass Index, Waist Circumference, Body Fat, Fasting Glucose in a Sample of Moroccan Adolescents Aged 11-17 Years. Journal of Nutrition and Metabolism, 2012, 1-7. http://dx.doi.org/10.1155/2012/510458

[28] Graves, L., Garnett, S.P., Cowell, C.T., et al. (2014) Waist-to-Height and Cardio-Metabolic Risk Factors in Adolescence: Findings from a Prospective Birth Cohort. Pediatric Obesity, 9, 327-338. http://dx.doi.org/10.1111/j.2047-6310.2013.00192.x

[29] Khourey, M., Manlhiot, C. and McCrindle, B.W. (2013) Role of the Waist/Height Ratio in the Cardio-Metabolic Risk Assessment of Children Classified by Body Mass Index. Journal of the American College of Cardiology, 62, 742-751.

[30] May, A.L., Kulina, E.V. and Yoon, P.W. (2012) Prevalence of Cardiovascular Disease Risk Factors among US Adolescents, 1999-2008. Pediatrics, 129, 1035-1041. http://dx.doi.org/10.1542/peds.2011-1082 